\title{
Extending the Applicability of Laser-Induced Breakdown Spectroscopy for Total Soil Carbon Measurement
}

\author{
Michael H. Ebinger,* M. Lee Norfleet, David D. Breshears, David A. Cremers, Monty J. Ferris, \\ Pat J. Unkefer, Megan S. Lamb, Kelly L. Goddard, and Clifton W. Meyer
}

\begin{abstract}
Soils are the major pool of terrestrial $\mathrm{C}$ globally. Estimating inventories and detecting changes in the soil $\mathrm{C}$ pool have remained elusive, largely because the spatial distribution of soil $\mathrm{C}$ varies considerably. New approaches are needed that enable more rapid, cost-effective, and sensitive measurements of soil $\mathbf{C}$ and that reduce uncertainty in estimates of $\mathrm{C}$ pools and changes in those pools. In this note we extend the application of a new method of total soil $\mathrm{C}$ measurement: laser-induced breakdown spectroscopy (LIBS). Carbon analysis using LIBS provides data in seconds from soils with little preparation, whereas conventional methods such as dry combustion require lengthy sample preparation and longer analysis times. Laser-induced breakdown spectroscopy instruments, unlike conventional instruments, can be used while in the field. This promising new method, however, has potential drawbacks, namely interference with $\mathrm{Fe}$ at approximately $248 \mathrm{~nm}$. Here we report results of using a different $C$ line at 193 nm to solve the interference problem. We also use a two-element standardization factor to demonstrate that the $193-\mathrm{nm}$ line is nearly as sensitive to $C$ concentration as the $C$ line at $247.8 \mathrm{~nm}$, and that calibration curves can be readily replicated. Overall these results indicate that LIBS is a very promising method to estimate soil $\mathrm{C}$ pools and dynamics.
\end{abstract}

Usion NCERTAINTY IN SOIL C POOLS is a major contributor to the overall uncertainty in balancing global and regional C fluxes (Greenland, 1998; Department of Energy [DOE], 1999; Lal et al., 1999; Falkowski et al., 2000; McCarty and Reeves, 2001). This fundamental uncertainty about the $\mathrm{C}$ cycle is also the focus of current and future international negotiations and treaties related to global change (Horwath et al., 2001; Paul et al., 2001; Scharpenseel et al., 2001). Quantifying soil pools and inventories remains a major challenge because of the high degree of inherent spatial heterogeneity in soil $\mathrm{C}$ and the lack of efficient approaches for quantifying soil C (DOE, 1999).

Improving soil $\mathrm{C}$ measurement is crucial to evaluate the permanence and to assure adequate monitoring and verification of sequestered soil C (Barford et al., 2001; Scholes and Noble, 2001). This issue of permanence focuses on the probability that $\mathrm{C}$ stored in terrestrial systems will be lost to the atmosphere, either through

M.H. Ebinger, D.D. Breshears, M.S. Lamb, K.L. Goddard, and C.W. Meyer, Earth and Environmental Science Division, Los Alamos National Laboratory, Los Alamos, NM 87545; M.L. Norfleet, USDA NRCS Soil Quality Institute, 411 South Donahue Drive, Auburn, AL 36832; D.A. Cremers and M.J. Ferris, Chemistry Divison, Los Alamos National Laboratory, Los Alamos, NM 87545; P.J. Unkefer, Bioscience Division, B-3, MS E529, Los Alamos National Laboratory, Los Alamos, NM 87545. REPORT LA-UR-01-6709. Received 7 Jan. 2002. *Corresponding author (mhe@lanl.gov).

Published in Soil Sci. Soc. Am. J. 67:1616-1619 (2003).

(c) Soil Science Society of America

677 S. Segoe Rd., Madison, WI 53711 USA changes in land use or disturbances such as fire or drought and the associated increases in erosion that can accompany them (Scholes and Noble, 2001; Breshears and Allen, 2002). Verification of $C$ storage focuses on accurately measuring small changes in terrestrial $\mathrm{C}$ pools and being able to distinguish sequestration from natural variation in $\mathrm{C}$ concentrations (Scholes and Noble, 2001). Reducing uncertainties associated with measurements of the soil $\mathrm{C}$ component of terrestrial $\mathrm{C}$ pools requires dramatic increases in the number of soil samples, which may not be economically feasible using current measurement technology. More efficient methods of measuring soil $\mathrm{C}$ must be developed to support improved estimates of terrestrial $\mathrm{C}$ inventories and fluxes for their effective management (National Resource Council [NRC], 1999).

A new method for measuring total soil $\mathrm{C}$, based on LIBS (Radziemski and Cremers, 1989; Moenke-Blankenburg, 1989; Rusak et al., 1997), was recently reported (Cremers et al., 2001). Initial calibration studies suggested that LIBS analysis could be a promising new method of soil $\mathrm{C}$ measurement for different soil types (Cremers et al., 2001). However, potential interferences between $\mathrm{Fe}$ and $\mathrm{C}$ lines at about $248 \mathrm{~nm}$ (Cremers et al., 2001) prompted evaluation of the 193-nm line of $\mathrm{C}$ where there are no interferences from $\mathrm{Fe}$ or other elements. Use of LIBS to measure soil C at either 247.8 or $193 \mathrm{~nm}$ could be an important new application. Deployment of a well-calibrated and robust LIBS instrument may provide the large number of accurate measurements needed to evaluate the importance of land-use strategies in terrestrial $\mathrm{C}$ sequestration efforts and verify possible $\mathrm{C}$ credits for commodities exchange. In addition, LIBS measurements can be made while in the field and could significantly improve the cost effectiveness of $\mathrm{C}$ measurements.

In this note, we evaluate the LIBS method using the strong $\mathrm{C}$ line at $193 \mathrm{~nm}$. Our main objectives were to evaluate the usefulness of the 193-nm C line and to determine if this interference-free $\mathrm{C}$ line improves or degrades LIBS results.

\section{MATERIALS AND METHODS}

\section{Soil Samples}

Soils with a relatively wide range in $\mathrm{C}$ concentrations and with similar chemical and physical properties were collected from two Aridic Argiustolls and an Aridic Paleustoll on three farms in eastern Colorado (Crabb, 1982; Petersen et al., 1986; Catlett, 2000; Cremers et al., 2001; Catlett et al., 2002). Six samples of the 18 were selected at random for calibration of

Abbreviations: DOE, Department of Energy; LIBS, Laser-Induced Breakdown Spectroscopy. 
the LIBS instrument. In addition, the remaining 12 samples were used to verify the relationship between $\mathrm{C}$ concentration measured by dry combustion using a Dohrmann DC-180 analyzer (Tekmar-Dohrmann, Mason, $\mathrm{OH}$ ) and LIBS using the $\mathrm{C}$ line at $193 \mathrm{~nm}$. Net intensity of the LIBS C line was recorded for each sample. In addition, intensities of the $\mathrm{Al}$ and $\mathrm{Si}$ peaks at approximately 199 and $212 \mathrm{~nm}$, respectively, were recorded. The ratio of the intensity of the $\mathrm{C}$ line to the sum of the $\mathrm{Al}$ and $\mathrm{Si}$ lines, $\mathrm{C} /(\mathrm{Al}+\mathrm{Si})$, was used as the standardized LIBS signal. This ratio minimized the shot-to-shot variation in the LIBS analyses. For each sample, the ratio was plotted with the concentration of soil $\mathrm{C}$ measured by dry combustion, a regression equation was estimated using LIBS and dry combustion data, and the resulting calibration curve was used to convert LIBS signal in the remaining samples to $\mathrm{C}$ concentrations. Calibration curves were plotted each day LIBS data were collected to monitor the reproducibility of the method.

\section{Analysis of Total Soil Carbon}

Subsamples of the $<2$-mm fraction were collected from field soils, weighed into sample boats, and analyzed for total soil C by dry combustion (Nelson and Sommers, 1982; Sollins et al., 1999; Robertson and Paul, 2000). Averages of three dry combustion measurements from each sample were used to calibrate the LIBS method. Separate samples of the same soils were analyzed by LIBS, and the data from both types of measurements were analyzed by linear regression methods. For the measurements reported here, we used the same apparatus and soils as described by Cremers et al. (2001) except for the different LIBS wavelengths noted above.

\section{RESULTS}

In the previous evaluation of soil $\mathrm{C}$ analysis by LIBS (Cremers et al., 2001), $\mathrm{Fe}$ and $\mathrm{C}$ lines overlapped at approximately $248 \mathrm{~nm}$; consequently, $C$ could not be quantified independently from Fe (Fig. 1a). Use of the $193-\mathrm{nm} \mathrm{C}$ line solved this difficulty by providing a clear $\mathrm{C}$ line without interferences (Fig. 1). The small line located on the right shoulder of the 193-nm C line (Fig. 1b) is from once-ionized $\mathrm{Al}(\mathrm{Al} \mathrm{II})$ and poses no difficulty for quantification of the C line at $193 \mathrm{~nm}$.

As expected, C measured by LIBS increased linearly with $\mathrm{C}$ concentrations as determined by dry combustion, and the two data sets were highly correlated $\left(r^{2}=0.99\right.$, $p<0.001$; Fig. 2a). The verification plot further demonstrates that the excellent relationship $\left(r^{2}=0.95, p<\right.$ 0.001 ) between LIBS and dry combustion data holds for all soils tested and that $\mathrm{Al}$ and $\mathrm{Si}$ concentrations remained nearly constant in each sample (Fig. 2b). Slopes of separate calibration curves plotted each day for $30 \mathrm{~d}$ of LIBS analyses were not significantly different (average $r^{2}=0.97, p<0.001$; data not shown) except for one curve $\left(r^{2}=0.82\right)$. This noted variation could have been due to operator error, instrumental error, or a combination of other factors. The repeated calibration curves demonstrated that the method was reproducible, at least with the samples chosen.

\section{DISCUSSION}

Our revision of the LIBS method begins to extend the applicability of this new approach for soil $\mathrm{C}$ mea-
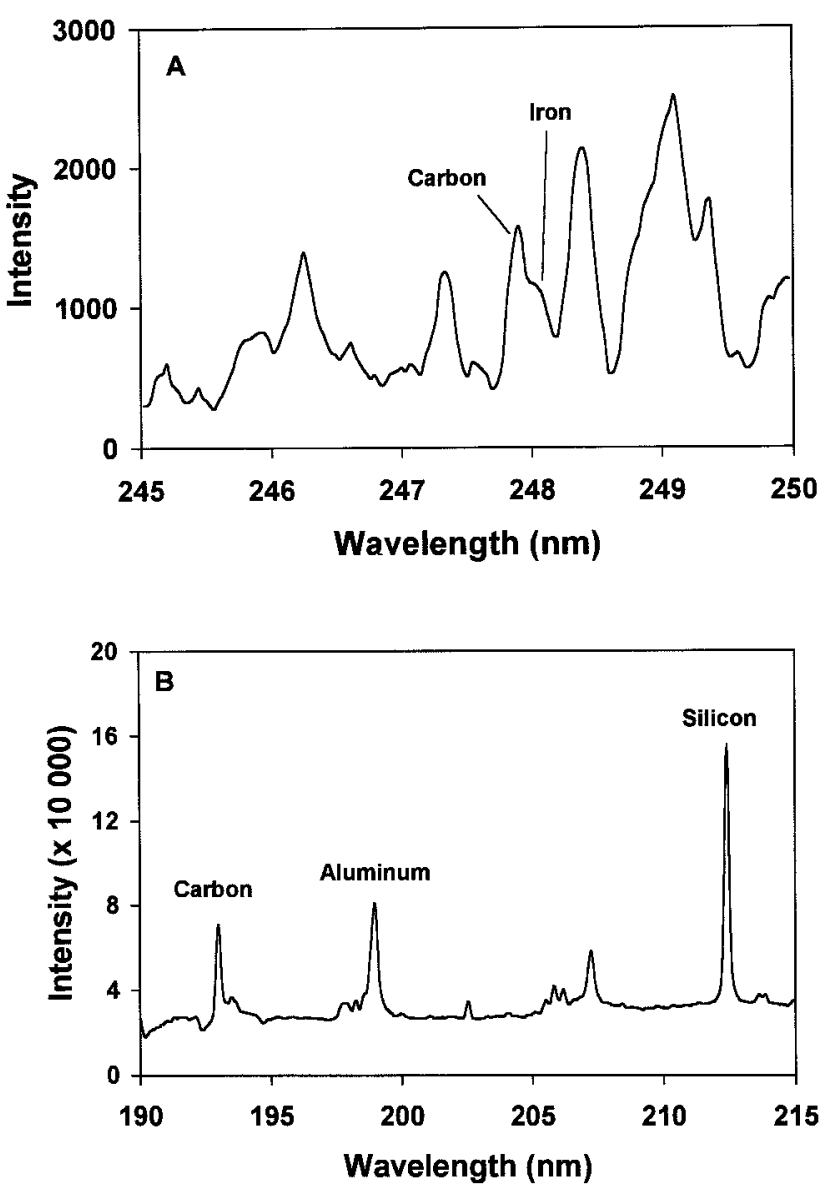

Fig. 1. (A) Region of laser-induced breakdown spectroscopy (LIBS) spectrum from 245 to $250 \mathrm{~nm}$ showing $C$ and $F e$ interferences at approximately $248 \mathrm{~nm}$. The line intensity of $C$ cannot be quantified independently from the $\mathrm{Fe}$ line, and this interference increases as Fe concentration increases. (B) Region of LIBS spectrum showing C line at $193 \mathrm{~nm}, \mathrm{Al}$ at $199 \mathrm{~nm}$, and $\mathrm{Si}$ at $212 \mathrm{~nm}$. The $\mathrm{C}$ line is easily quantified without interference from other elements. Aluminum and Si lines were also easily quantified and were used as standardizing factors.

surement. Using the $\mathrm{C}$ line at $193 \mathrm{~nm}$ rather than the original line at $247.8 \mathrm{~nm}$, we removed the C-Fe interference. Iron, like some other elements, has a high density (emission lines/wavelength range) of emission lines. We found that the $\mathrm{C}$ line at $193 \mathrm{~nm}$ can be used to observe $\mathrm{C}$ emission unambiguously using a lower resolution spectrograph, such as might be incorporated into a fieldportable system. In our analysis, the $\mathrm{C}$ and $\mathrm{Si}$ lines are due to neutral species, whereas the $\mathrm{Al}$ emission results from an ionized species. In general, emissions from neutral and ionized species maximize at different times following plasma formation. However, by using a gated detector with a wide gate pulse (e.g., $20 \mu \mathrm{s}$ ), strong emissions from both species were observed simultaneously. In this standardization procedure, variations in the intensities of the emission lines due to differences in ablated material and excitation conditions should be similar so that the ratio is more consistent than the raw intensity of the $\mathrm{C}$ line alone. Variation of the $\mathrm{C} /(\mathrm{Al}+$ $\mathrm{Si}$ ) ratios from different samples can then be attributed to actual differences in the $\mathrm{C}$ concentrations between the samples. 

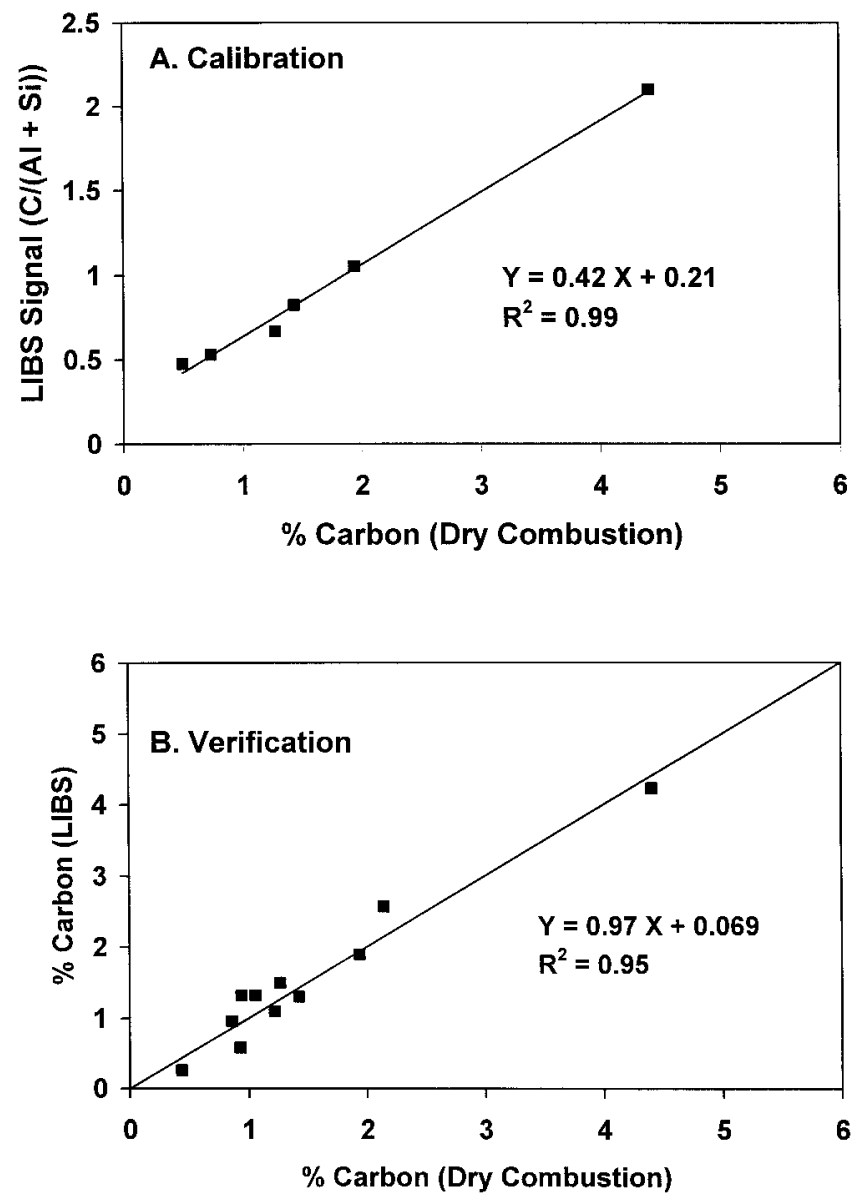

Fig. 2. (A) Calibration of laser-induced breakdown spectroscopy (LIBS) using data from the calibration set soils $\left(r^{2}=0.99, p<\right.$ 0.001; $n=6)$. Quantitative data from the ratio, $\mathrm{C} /(\mathrm{Al}+\mathrm{Si})$, of $\mathrm{C}$ line at $193 \mathrm{~nm}$ to the sum of the Al line at $199 \mathrm{~nm}$ and $\mathrm{Si}$ line at $212 \mathrm{~nm}$. (B) Plot of the LIBS data from the verification set of the Colorado soils $\left(r^{2}=0.95, p<0.001 ; n=12\right.$; two points nearly coincident). Slopes of calibrations curves plotted each of $30 \mathrm{~d}$ were not significantly different.

The sum of $\mathrm{Al}$ and $\mathrm{Si}$ line intensities used as standardization factors may make the analytical signal more robust and more generally applicable than either element alone. Ideally, the internal standard should be constant within the suite of soil samples analyzed. Here we assume that the sum of $\mathrm{Al}$ and $\mathrm{Si}$ intensities in the samples is constant, or nearly so, because of the similar morphology of the Colorado samples. When soil texture changes within a set of samples, though, the proportion of $\mathrm{Al}$ to $\mathrm{Si}$ also changes according to the mineralogy. Silicon is expected to increase relative to $\mathrm{Al}$ when texture becomes coarser and the sand component increases, especially when that fraction is siliceous. As soils become more clayey, Al should increase relative to $\mathrm{Si}$ with increasing amounts of 1:1 and 2:1 layer silicates. Through soil mineral weathering and the subsequent loss of bases, both $\mathrm{Si}$ and $\mathrm{Al}$ may increase overall with Si predominant in sandier soils and $\mathrm{Al}$ increasing in intensity as soils become finer. With soils of similar morphology such as the Colorado soils used here, the shift of Si relative to Al with texture should be minimal. The calibration and verification data support this assumption, and the daily reproducibility of the calibration curves with the Colorado soils illustrates the robustness of the instrument. Additional testing will be required to evaluate fully the use of various standardizing factors from a wider range of soils, but our calibration and verification data are promising. The apparent consistency of the soil matrices from the Colorado samples strengthens the correlation between the $\mathrm{C}$ concentrations measured by LIBS and dry combustion methods.

\section{CONCLUSIONS}

It is clear from initial studies (Cremers et al., 2001) and additional results reported in this note that LIBS is a powerful analytical tool for measuring total soil C. We demonstrate that Fe does not interfere with the 193$\mathrm{nm} C$, that it varies predictably with known C concentrations in calibration samples and unknowns, and that analysis at $193 \mathrm{~nm}$ is as reproducible as the method at $247.8 \mathrm{~nm}$. The information in this note supports use of the LIBS method at $193 \mathrm{~nm}$ and compliments previous work at $247.8 \mathrm{~nm}$. The main advantages of LIBS analysis over conventional methods such as dry combustion include more rapid sample analysis without sacrifices in precision or accuracy and reduced need for sample preparation. Soil C measurement while in the field is also a potential advantage of LIBS, although this application has yet to be tested fully. Analysis of soil C by LIBS corresponds to data averaged from 10 or more points of about $1 \mathrm{~mm}$ in diameter. The rapid analysis and ease of use in the field, however, mean that thousands of measurements might be easily obtained to characterize soil heterogeneity and variation in $\mathrm{C}$ distribution within soils, to predict soil $\mathrm{C}$ dynamics, and to estimate $\mathrm{C}$ pool sizes with better quantification of myriad uncertainties. Quantifying these uncertainties is a central issue in the development of international treaties concerning $\mathrm{C}$ management and global change. Overall, our results suggest that the LIBS method, as modified and reported in this study, is a promising method for complimenting conventional analyses and for advancing the measurement of soil $\mathrm{C}$ pools and dynamics.

\section{ACKNOWLEDGMENTS}

This work was supported jointly by the DOE National Energy Technology Laboratory and UDSA National Resource Conservation Service, and builds on initial research supported by DOE Office of Science (OBER). The authors thank the anonymous reviewers and the associate editor for valuable comments on this paper.

\section{REFERENCES}

Barford, C.C., S.C. Wofsy, M.L. Goulden, J.W. Munger, E.H. Pyle, S.P. Urbanski, L. Hutyra, S.R. Saleska, D. Fitzjarrald, and K. Moore. 2001. Factors controlling long- and short-term sequestration of atmospheric $\mathrm{CO}_{2}$ in a mid-latitude forest. Science 294: $1688-1691$.

Breshears, D.D., and C.D. Allen. 2002. The importance of rapid, disturbance-induced losses in carbon management and sequestration. Global Ecol. Biogeogr. 11:1-5.

Catlett, K.M. 2000. The role of organic matter and other soil properties in $\mathrm{Zn}^{2+}$ activity and AB-DTPA-extractable $\mathrm{Zn}$ in Soils. Ph.D. diss. 
Dep. of Soil and Crop Sciences, Colorado State University, Ft. Collins, CO.

Catlett, K.M., D.M. Heil, W.L. Lindsay, and M.H. Ebinger. 2002. Effects of soil chemical properties on Zinc ${ }^{2+}$ activity in 18 Colorado soils. Soil Sci. Soc. Am. J. 66:1182-1189.

Crabb, J.A. 1982. Soil Survey of Weld County, Colorado, North Part. USDA, Soil Conservation Service, Washington, DC.

Cremers, D.A., M.H. Ebinger, D.D. Breshears, P.J. Unkefer, S.A. Kammerdiener, M.J. Ferris, K.M. Catlett, and J.R. Brown. 2001. Measuring total soil carbon with laser-induced breakdown spectroscopy (LIBS). J. Environ. Qual. 30:2202-2206.

Department of Energy (DOE). 1999. Carbon sequestration research and development. DOE Report DOE/SC/FE-1, Washington, DC (Available on-line at http://www.ornl.gov/carbon_sequestration). DOE, Washington, DC

Falkowski, P., R.J. Scholes, E. Boyle, J. Canadell, D. Canfield, J. Elser, N. Gruber, K. Hibbard, P. Högberg, S. Linder, F.T. Mackenzie, B. Moore, III, T. Pedersen, Y. Rosenthal, S. Seitzinger, V. Smetacek, and W. Steffen. 2000. The global carbon cycle: A test of our knowledge of Earth as a system. Science 290:291-296.

Greenland, D.J. 1998. Carbon sequestration in soil: Knowledge gaps indicated by the symposium presentations. p. 591-594. In R. Lal et al. (ed.) Soil processes and the carbon cycle. CRC Press, Boca Raton, FL.

Horwath, W.R., C. van Kessel, U. Hartwig, and D. Harris. 2001. Use of ${ }^{13} \mathrm{C}$ isotopes to determine net carbon sequestration in soil under ambient and elevated $\mathrm{CO}_{2}$. p. 221-232. In R. Lal et al. (ed.) Assessment methods for soil carbon. Lewis, Boca Raton, FL.

Lal, R., J.M. Kimble, R.F. Follett, and C.V. Cole. 1999. The potential of U.S. cropland to sequester carbon and mitigate the greenhouse effect. CRC Press, Boca Raton, FL.

McCarty, G.W., and J.B. Reeves, III. 2001. Development of rapid instrumental methods for measuring soil organic carbon. p. 371380. In R. Lal et al. (ed.) Assessment methods for soil carbon. Lewis, Boca Raton, FL.
Moenke-Blankenburg, L. 1989. Laser Microanalysis. John Wiley, New York.

National Research Council (NRC). 1999. A U.S. carbon cycle science plan. p. 7-18. In J.L. Sarmiento and S.C. Wofsy (ed.) U.S. Global Change Research Program, Washington, DC.

Nelson, D.W., and L.E. Sommers. 1982. Total carbon, organic carbon, and organic matter. p. 539-579. In A.L. Page et al. (ed.) Methods of soil analysis. Part 2. 2nd ed. ASA and SSSA, Madison, WI.

Paul, E.A., S.J. Morris, and S Böhm. 2001. The determination of soil C Pool Sizes and turnover rates: Biophysical fractionation and tracers. p. 193-206. In R. Lal et al. (ed.) Assessment methods for soil carbon. Lewis, Boca Raton, FL.

Petersen, M.L., J.A. Crabb, and R.J. Larsen. 1986. Soil Survey of Washington County, Colorado. USDA Soil Conservation Service, Washington, DC.

Radziemski, L.J., and D.A. Cremers. 1989. Spectrochemical analysis using laser plasma excitation. p. 295-325. In L. J. Radziemski and D.A. Cremers (ed.) Applications of laser-induced plasmas. Marcel Dekker, New York.

Robertson, G.P., and E.A. Paul. 2000. Decomposition and soil organic matter dynamics. p. 104-116. In O.E. Sala et al. (ed.) Methods in ecosystem science. Springer, New York.

Rusak, D.A., B.C. Castle, B.W. Smith, and J.D. Winefordner. 1997. Fundamentals and applications of laser-induced breakdown spectroscopy. Crit. Rev. Anal. Chem. 27:257-290.

Scharpenseel, H.W., E.M. Pfeiffer, and P. Becker-Heidmann. 2001. Ecozone and soil profile screening for C-residence time, rejuvenation, bomb ${ }^{14} \mathrm{C}$ Photosynthetic $\delta^{13} \mathrm{C}$ Changes. p. 207-219. In R. Lal et al. (ed.) Assessment methods for soil carbon. Lewis, Boca Raton, FL.

Scholes, R.J., and I.R. Noble. 2001. Climate change: storing carbon on land. Science 294:1012-1013.

Sollins, P., C. Glassman, E.A. Paul, C. Swanston, K. Lajtha, J.W. Heil, and E.T. Elliott. 1999. Soil carbon and nitrogen: pools and fractions. p. 89-105. In G.P. Robertson et al. (ed.) Standard soil methods for Long-Term Ecological Research. Oxford University Press, New York. 